\title{
La descontextualización de los gestos en el arte románico de los reinos hispanos*
}

\author{
Alicia MiguÉLEZ CAVERO \\ Doctora en Historia del Arte
}

RESUMEN. La diversidad semántica de muchas de las conductas gestuales representadas en la iconografía románica nos lleva a plantear la existencia de un fenómeno particular, el de la descontextualización del gesto. Dicho fenómeno puede deberse, principalmente, a dos motivos, uno casual y otro intencionado. El objetivo de este trabajo es analizar ambos.

Palabras clave: Gestos, Iconografía, Arte románico, Península Ibérica.

ABSTRACT. The semantic diversity of many of the gestures we can find in the Romanesque iconography leads us to suggest the existence of a particular phenomenon: the gesture decontextualization. This phenomenon can be caused by two motives, one of them casual and the other one deliberate. The aim of this paper is to analyse both of them.

Key words: Gestures, Iconography, Romanesque Art, Iberian Peninsula.

Analizando el significado de los gestos presentes en la iconografía románica de los reinos hispanos, podemos señalar la existencia de dos tipos de actitudes gestuales ${ }^{1}$ : por un lado, aquellas conductas que

* Este trabajo es una derivación y profundización de aspectos que he analizado en la Tesis Doctoral que he realizado sobre el tema "Gesto y gestualidad en el arte románico de los reinos hispanos: lectura y valoración iconográfica", dirigida por la Prof. Dra. Etelvina Fernández González y defendida en la Universidad de León el 12 de noviembre de 2009. El tribunal que juzgó el trabajo estuvo formado por los doctores: M. Valdés Fernández (Universidad de León), I. B. Bango Torviso (Universidad Autónoma de Madrid), M. C. Muñoz Párraga (Universidad Autónoma de Madrid), M. A. Miranda (Universidade Nova de Lisboa) y M.
C. Cosmen Alonso (Universidad de León). Recibió la calificación de Sobresaliente cum Laude por unanimidad y Mención Europea; recientemente, ha sido galardonada con el Premio de Tesis Doctorales que anualmente concede la asociación Círculo Románico, en su convocatoria del año 2009. Gracias a ello será publicada en toda su extensión próximamente.

${ }^{1}$ Desde el punto de vista lingüístico, al analizar las conductas gestuales hemos de distinguir entre los conceptos de gesto y postura. El gesto tiene siempre un carácter dinámico, implica un movimiento; sin embargo la postura es estática. Por ello, lo que podemos hallar siempre en una imagen medieval son posturas. A pesar de ello, la mayoría de los estudios realizados sobre la gestualidad en distintas disciplinas se han decantado, casi siempre, por la utilización del término gesto de manera genérica. En el campo de las ciencias humanísticas, los distintos autores que se han ocupado del estudio de estos aspectos en época me- 
conllevan un solo significado y, por otro, aquellas que pueden acoger diversas cargas semánticas.

En cuanto al primer tipo, se trata de gestos susceptibles de ser utilizadas en diversos contextos, situaciones, escenas y temas iconográficos $\mathrm{y}$, además, ser adoptados por diversos personajes. Sin embargo, mantienen siempre el mismo valor semántico. Es el caso, por ejemplo, del gesto que realiza un personaje que coge a otro por la muñeca: la figura de Dios toma a Eva por la muñeca para sacarla del costado de Adán en la representación miniada en el Livro das $A v e s^{2}$; Jesús coge por la muñeca a una figura masculina en la imagen de la Anástasis esculpida en el pórtico de la basílica de San Andrés de Armentia (Álava) (Fig. 1) ${ }^{3}$; y en un capitel de la Real Colegiata de San Isidoro de León, una dextera dei ase la mano del propio Cristo inserto en una mandorla ${ }^{4}$. Nos encontramos ante un comportamiento gestual que se produce en diferentes escenas y contextos iconográficos, aunque siempre con un mismo significado: los personajes que lo realizan indican con su postura una intención determinada, la de dirigir de un lugar a otro a la figura cuya muñeca asen.

dieval también utilizan el término gesto de manera genérica. Es el caso de los trabajos de: F. GARNIER, Le langage de l'image au Moyen Âge. Signification et symbolique, Tours, 1995 ; ID., Le language de l'image au Moyen Âge II. Grammaire des gestes, París, 2003 y J. C. SCHMITT, La raison des gestes dans l'Occident médiéval, Paris, 1990. Por nuestra parte, en este trabajo haremos un uso también general del término y utilizaremos los conceptos de postura, conducta y comportamiento como sinónimos del mismo, con el fin de hacer más ágil la lectura.

${ }^{2}$ Lisboa, Arquivo Nacional da Torre do Tombo, Casa Forte 90, antepenúltimo folio, verso.

${ }^{3}$ La advocación actual de la basílica es San Prudencio.

${ }^{4}$ El capitel se halla situado en el tercer pilar del lado norte de la iglesia de la Colegiata.
En cuanto al segundo tipo, se trata de gestos que acogen varios sentidos $\mathrm{y}$ son susceptibles de ser adoptadas, asimismo, por distintos personajes. Estamos, en estos casos, ante significados que pueden ser similares o bien diametralmente opuestos ${ }^{5}$. Podemos señalar, como ejemplo representativo en la iconografía románica de los reinos hispanos, la representación de un personaje que coloca una mano en su barba, postura que alude al gesto de mesarse la barba. Puede tener significados plurales y ser realizado por personajes en distintos contextos, aunque podemos señalar tres sentidos principales: se trata de un gesto que puede aludir a la reflexión, al sentimiento de dolor o ser asociado al concepto de la virilidad masculina ${ }^{6}$.

\footnotetext{
${ }^{5}$ Esta categoría sería muy similar a la que, en el campo de la antropología, Desmond Morris denomina los gestos multimensajes, ya que tienen un número variado de significados totalmente distintos, en función del momento y el lugar. Cfr.: D. MORRIS, Manwatching. A Field Guide to Human Behavior, New York, 1977, pp. 41-42.

${ }^{6} \mathrm{M}$. Barasch, al estudiar este gesto, señala que puede ser analizado también como un señal de gran tensión, adoptado por figuras de herejes o vencidos. Además, hace alusión a que se trata de una actitud que puede ser también llevada a cabo por personajes sagrados, como Moisés. En este caso, sería una postura que plasmaría el sobrecogimiento ante la presencia divina. Cfr.: M. BARASCH, Gestures of Despair in Medieval and Early Reinassance, New York, University Press, 1976, p. 18. Sobre este gesto puede verse también los estudios de: C. BOUILLOT, «La chevelure: la tirer ou l'arracher, étude d'un motif pathétique dans l'épique médiéval», La chevelure dans la littérature et l'art du Moyen Âge, études réunis par Chantal CannochieBourgne, Actes du $28^{e}$ Colloque du CUERMA, 20-22 février 2003, Senefiance, 50, Aix-en-Provence, 2004, pp. 35-36 ; M. A. ForNes PALLICER - M. PUIG RODRIGUEZESCALONA, «La gestualidad de la barba y el mentón en la Antigüedad romana», Revista de Estudios Latinos, 5, 2005, pp. 175-192; F. GARNIER, Le langage de l'image..., vol. 2, pp. 90-91; J. NUÑo GONZALEZ, «Hacia una visión de la iconografía sexual: escenas procaces y figuras obscenas», Poder y seducción de la imagen románica, Aguilar de Campoo, 2006, p. 207 y R. SÁNCHEZ AMEIJEIRAS, «Ecos de la Chanson de Roland en la iconografía del sepulcro de doña Blanca en santa
} 
Debido precisamente a esa diversidad, es difícil identificar su contenido semántico en todas las obras en las que aparece. Así, podemos citar varios casos en los que es realmente ardua la tarea de averiguar exactamente su sentido. Uno de los ejemplos lo hallamos en el Codex Calixtinus. Se trata de la miniatura en la que se narra, plásticamente, la salida de Carlomagno desde Aquisgrán hacia España ${ }^{7}$. En el registro intermedio de la miniatura hallamos varias figuras armadas con espadas y lanzas. Aunque los cuerpos de todas ellas están situados frontalmente, las cabezas $\mathrm{y}$ pies se dirigen hacia la derecha del espectador. Este hecho, junto con el de que dos de los personajes señalen con su dedo índice también hacia la derecha, indica su intención de movimiento y su dirección. Pues bien, el personaje situado en tercer lugar desde la izquierda, un guerrero, se lleva su mano diestra a una barba larga y poblada.

El segundo de los casos al que nos referimos se encuentra en un capitel de una de las pilastras en la panda sur del claustro de la catedral rosellonense de Elna (Fig. 2). En su cara oriental se representó una escena que, tradicionalmente, ha sido identificada como el momento en el que Herodes ordena a sus soldados la matanza de los inocentes. Podemos ver la representación de un rey en el extremo derecho de la composición, sedente, que extiende su brazo y dedo índice hacia dos personajes, armados, y uno vestido con cota de malla, que están situados ante él. Tras ellos hay otro grupo de cuatro figuras masculinas y tres caballos. Los hombres están también armados y ataviados con atuendo militar. El que está situado en último lugar se lleva la mano hacia una barba puntiaguda, al igual que

María la Real de Nájera», Lecturas de Historia del Arte, 2, 1990, pp. 206-214, especialmente p. 208.

${ }^{7}$ Santiago de Compostela, Archivo de la Catedral, s. n., fol. 162v. ocurre con el personaje descrito del Codex Calixtinus.

En tercer lugar, hallamos también esta actitud en la representación de una figura esculpida en el fuste de una columna hoy conservada en el Museo Diocesano de Solsona, relacionada, estilísticamente, con las piezas procedentes del claustro de la catedral de dicha localidad catalana. Se trata de una figura masculina, ataviada con una túnica corta, que sostiene una maza en alto con la mano derecha y se toca una barba puntiaguda con la izquierda. Aunque no lleva arma defensiva, podemos identificarla como un soldado o un guerrero.

En los tres ejemplos señalados, como decíamos, se nos hace difícil señalar claramente cuál es el significado exacto de este gesto $^{8}$. Por ello, a fin de descifrar el sentido concreto que el gesto tiene en una imagen o escena determinada, debemos tener en cuenta los demás componentes que conforman la imagen, así como el propio contexto en el que ésta fue elaborada ${ }^{9}$. Éstos

\footnotetext{
${ }^{8}$ J. Camps, al analizar el caso catalán, lo compara con la referida miniatura del Codex Calixtinus y señala la posibilidad de que se trate de un signo de derrota, en relación con el significado de dolor y aflicción que puede acoger el gesto de tocarse la barba. Cfr.: J. CAMPS, «Fust de columna», Museu Diocesà i Comarcal de Solsona. Catàleg d'Art Romànic i Gòtic, Barcelona, 1990, ficha catalográfica 46, p. 117. En cambio, F. Garnier, quien analiza el gesto del soldado en la miniatura gallega, propone que se trata de una conducta que alude a la perplejidad, la incertidumbre de un guerrero que parte hacia el combate en tierras lejanas. Véase la teoría de este autor en: F. GARNIER, Le langage de l'image...II, p. 90.

${ }^{9}$ Este es un aspecto tratado también en otras áreas de conocimiento donde la gestualidad tiene un papel primordial. En este sentido, en el campo de la lingüística y la semiótica, se concede un papel importante al contexto en el que se generan los gestos. Así lo ha señalado, por ejemplo, P. Magli, cuando afirma que "Los gestos no son bloques de comportamientos aislados; no son unidades expresivas dotadas de significantes explícitos e invariables, sino secuencias sintácticas que se cargan de sentido solamente dentro de un contexto que tenga en cuenta el comportamiento global del emisor y la situación en
} 
nos ofrecen la posibilidad de decantarnos por uno u otro de los significados posibles.

Sin embargo, cuando analizamos obras artísticas románicas, en muchos casos nos hallamos ante imágenes que se hallan desligadas del contexto primigenio en el que fueron creadas, de manera que la limitación interpretativa que acabamos de señalar se ve intensificada todavía más. Este hecho nos ha dado pie para analizar un fenómeno particular, el de la descontextualización del gesto en la iconografía románica $y$, de manera particular, en la plástica románica de los reinos hispanos. Se trata de un fenómeno que podemos atribuir a dos motivos: uno de carácter "casual" y otro, en cierta manera, "intencionado".

\section{LA DESCONTEXTUALIZACIÓN CASUAL DEL GESTO}

La descontextualización casual del gesto está relacionada, fundamentalmente, con aspectos asociados al devenir del tiempo y los avatares que éste impone a toda obra artística. Debido a estos factores, actualmente existen un gran número de obras que han sufrido un deterioro importante o han sido trasladadas desde su ubicación original. Por ello las atribuciones, interpretaciones e identificaciones que se pueden realizar son muy variadas.

La primera causa de descontextualización, meramente causal, está relacionada con aquellas obras de arte que hoy podemos contemplar en museos y galerías de arte. Han sido transportadas desde su lugar de origen $y$, en muchos casos, desligadas del programa iconográfico completo en el que estaban insertas, lo que da lugar, en

la cual este comportamiento se produce. Sólo considerando el contexto y la situación enunciativa en los cuales se manifiesta un sintagma gestual, es posible reducir la rica polisemia del gesto". Sobre estos aspectos véase: P. MAGLI, «Para una semiótica del lenguaje gestual», Los Gestos. Sentidos y prácticas, De Signis, 3, 2002, pp. 37-52. muchas ocasiones, a una pérdida lógica del significado de posturas y actitudes. Podemos citar un ejemplo elocuente en la figura aislada procedente del programa pictórico de San Clemente de Taüll, que hoy se encuentra formando parte de la colección de arte románico del Museo Nacional de Arte de Cataluña. Es un personaje masculino y sedente que apoya su cabeza ladeada en la mano cuyo brazo es apoyado, a su vez, en el muslo.

Ese gesto, el de colocar la mano a la altura de la mejilla, puede tener en la iconografía románica varios significados ${ }^{10}$ : puede ser utilizado para representar el estado del sueño, en personajes dormidos; puede también aludir a un sentimiento, el del dolor y sufrimiento interno; $y$, por último, se trata de una postura bastante frecuente en la representación de personajes sabios, que manifiestan con esta conducta un estado de reflexión y pensamiento. Debido a esta pluralidad de significados, tanto la identificación como el significado de la actitud del personaje representado en el programa catalán son verdaderamente difíciles de discernir, sobre todo si añadimos que el personaje no lleva ningún otro atribuyo o inscripción aclaratoria ${ }^{11}$.

-

${ }^{10}$ Se trata de uno de los gestos más utilizados por los artistas de época románica, asociado a infinidad de significantes $\mathrm{y}$, como decimos, a tres significados principales. Sobre él puede consultarse el estudio que hemos realizado en: A. MiguÉlez CAVEro, Actitudes gestuales en la iconografía del románico peninsular hispano. El sueño, el dolor espiritual y otras expresiones similares, León, 2007.

${ }^{11}$ A ello hay que añadir que no se sabe el lugar exacto que ocupaba en el conjunto del programa iconográfico de Taüll.. El hecho de desmontar las pinturas de su lugar de origen, su traslado y posterior nuevo montaje en el museo catalán es la causa, probablemente, de la descontextualización y pérdida del significado original de este gesto. Así, esta figura ha sido identificada como Jacob, el rico Epulón en el infierno, el santo Job o Efraín. El sentido del gesto ha sido relacionado con la plasmación gráfica del dolor interno. Sobre todas estas hipótesis véase: M. PAGÈS I 
En segundo lugar, es posible hallar también la descontextualización casual del gesto en piezas sacadas de su contexto iconográfico original pero conservadas in situ, en el mismo monumento, edificio o pieza para el que fueron creadas. Así, por ejemplo, en la portada de la fachada occidental de la iglesia de Santa María de Sangüesa se encuentra una figura suelta que está sentada y se lleva una mano a la mejilla (Fig. 3). Esta figura, sacada de su ubicación y contexto original, ha perdido el sentido y significado real de su actitud y de su gesto.

Por último, la tercera de las causas de descontextualización casual está asociada con el propio deterioro físico in situ del material, soporte o medios artísticos utilizados para la elaboración de las obras de arte. En este sentido, los programas pictóricos pueden verse mermados con el paso del tiempo y la escultura puede desgastarse o descomponerse. Un ejemplo de este tipo de deterioro, que lleva a una interpretación difícil del gesto, la observamos en un relieve rectangular empotrado en exterior del ábside del lado del evangelio de la iglesia de San Cipriano (Zamora) (Fig. 4). En él se esculpió, en el siglo XII, una figura recostada, que se lleva una mano a la mejilla. Nos encontramos, ante la plasmación del gesto de colocar la mano a la altura del pómulo que, como hemos señalado, puede tener diversos significados en la iconografía románica. A ello debemos añadir la poca definición escultórica que tiene hoy el relieve, desgastado por el paso del tiempo, lo que hace ciertamente complicada una identifi-

PARETAS, «Sobre la identificación d'una figura aïllada de l'absis de Sant Climent de Taüll», Butlletí del Museu Nacional d'Art de Catalunya, 4, 2000, pp. 195-112 e ID., «El valle de Boí. Historia y arte: sobre la construcción y decoración de sus iglesias románicas», Obres mestres del romànic. Escultures de la Vall de Boí, Barcelona, 2004, pp. 97-99, especialmente p. 98. cación correcta tanto de la figura como de la actitud que adopta ${ }^{12}$.

\section{LA DESCONTEXTUALIZACIÓN INTENCIONADA}

Como hemos señalado anteriormente, la descontextualización del gesto puede deberse también a causas más o menos intencionadas. En este sentido, es posible hallar dos tipos de situación, ambas asociadas al papel del artista.

En primer lugar existir la posibilidad de que el artista malinterprete o desconozca la variedad de sentidos que puede adquirir un mismo gesto y que lo utilice sin tenerlos en cuenta, por puro desconocimiento o por hábito. De esta manera, la postura pierde todo su contenido semántico. En este sentido, debemos también tener en cuenta la pericia y capacidad técnica del artista a la hora de plasmar gráficamente un tema o motivo, sobre todo en temas que son muy similares desde el punto de vista formal.

Como ejemplo de este tipo de descontextualización, podemos señalar dos conductas asociadas con el tronco y los brazos que, formalmente, son muy similares entre sí. Por un lado el combate cuerpo a cuerpo, representado generalmente en el arte románico a partir de dos personajes enfrentados que luchan con sus brazos. Por otro lado, el gesto del abrazo, que también implica la presencia de dos figuras de perfil, que extienden sus brazos la una hacia la otra como una muestra o manifestación afectiva. Aunque se trata de fórmulas plásticas similares, el sentido y significado de cada una de ellas nos lleva por derroteros diversos. Por ello, la habilidad técnica del

\footnotetext{
${ }^{12} \mathrm{~J}$. M. Rodríguez propone la representación de una figura bien adormilada o bien pensativa. Cfr.: J. M. RODRÍGUEZ MONTAÑÉS, «Iglesia de San Cipriano», Enciclopedia del Románico en Castilla y León. Zamora, Aguilar de Campoo, 2002, pp. 370-380, especialmente pp. 375-376.
} 
artista a la hora de representar ambos temas puede conllevar en determinados casos una descontextualización del significado de la imagen y, más concretamente, de los gestos incluidos en ella. Al tratarse de motivos iconográficos tan parecidos desde el punto de vista formal, existen escenas y obras en las que es difícil llegar a discernir el tema que el artista románico quiso representar.

Señalaremos dos ejemplos concretos: uno de ellos se encuentra esculpido en la pila bautismal de la iglesia de San Juan Bautista en Guardo (Palencia) ${ }^{13}$. Se trata de dos figuras situadas de perfil, una mirando hacia la otra, que tienen una pierna avanzada y se cogen por los brazos. Una de ellas lleva el cabello corto y la otra algo más largo, por lo que podríamos identificarlos como un hombre y una mujer próximos a abrazarse. Sin embargo, ambos tienen el torso desnudo y van ataviados, únicamente, con un faldellín corto. Éste es un atributo que nos remite a escenas de luchadores muy habituales en la iconografía románica. Por todo ello, podemos considerar esta imagen como ambivalente en su significado, ya que podría aludir bien a una escena de carácter amoroso o bien bélico. Aún así, teniendo en cuenta otras representaciones de este tipo de combate en pilas bautismales románicas cercanas a la de Guardo, como la de Rebanal de las Llantas, creemos que quizá podríamos decantarnos por la identificación de un combate cuerpo a cuerpo. Sin embargo, este ejemplo nos muestra cómo el gesto deja de ser el elemento fundamental que permite al espectador analizar la imagen que tiene ante sí, de manera que éste debe fijarse en otros motivos o elementos, y e intentar buscar obras afines que le permitan deshacer la

\footnotetext{
${ }^{13}$ Sobre esta pila véase: A. M. MARTínEZ TEJERA, «Guardo», Enciclopedia del Románico en Castilla y León. Palencia. Vol. I, Aguilar de Campoo, 2002, pp. 645-646.
}

ambigüedad gestual, iconográfica y temática ante la que se encuentra.

Otro de las muestras de este tipo de descontextualización la hallamos en un canecillo de la cabecera del templo de San Claudio de Olivares (Zamora) (Fig. 5). En este caso, nos encontramos ante dos personajes situados de frente. Se trata de dos hombres barbados que se cogen por la muñeca mientras que uno de ellos levanta su brazo derecho, como si se dispusiera a atacar al otro. Sin embargo, se trata de un canecillo de una calidad escultórica bastante deficiente, de manera que la interpretación correcta de la escena representada es complicada. Por ello, ante esta imagen no nos decantamos, de momento, por ninguna de las opciones de identificación ${ }^{14}$.

Por otro lado, la segunda de las causas de descontextualización "intencionada" del gesto está asociada a una actitud mucho más deliberada por parte del artista. Creemos que existen casos en los que éste, de manera intencionada, despoja a un determinado gesto de su significado habitual. Con respecto a este hecho, creemos relevante subrayar la importancia que debieron tener, en este momento, los libros, plantillas y hojas de modelos, de donde los artistas tomaban ideas gráficas para las escenas e imágenes que debían componer ${ }^{15}$. No es

\footnotetext{
${ }^{14}$ J. M. Rodríguez Montañés lo identifica como "dos personajes barbados en actitud de lucha (uno ase al otro por la muñeca)". Cfr.: J. M. RODRíGUEz MONTAÑÉS, «Iglesia de San Claudio de Olivares», Enciclopedia del Románico en Castilla y León, Aguilar de Campoo, 2002, pp. 400-410, especialmente ilustración en p. 401 y texto en p. 403.

${ }^{15}$ Durante todo el período medieval, parece claro que los artistas dispusieron habitualmente de hojas o plantillas de modelos de las que copiaban figuras y escenas de obras que veían, con el objetivo de utilizarlas después en obras suyas posteriores. Los artistas viajaban continuamente para encontrar trabajos y encargos artísticos nuevos, de manera que la circulación de modelos $\mathrm{y}$, con ellos, de gestos, fue fácil y relativamente rápida. En la Península Ibérica, además,
} 
difícil imaginar que los escultores utilizaran también estos modelos como meros elementos aislados de cualquier composición, únicamente como un recurso ornamental más.

Como muestra podemos señalar un canecillo situado en el exterior de la iglesia burgalesa de Nuestra Señora la Antigua de Butrera, en el que se esculpió una figura sedente que se lleva una mano a la mejilla. Se trata de una figura similar a la que hallamos en el interior de la iglesia, en un relieve que plasma gráficamente la Epifanía y en el que José, sedente, ladea su cabeza y la apoya en la mano ${ }^{16}$ (Fig. 6). Creemos que el artista o taller que realizó el programa escultórico de esta iglesia utilizó un modelo similar para la representación de José, donde el gesto tiene un significado más concreto, y la figura del canecillo exterior, donde

hemos de tener en cuenta el papel desempeñado por el Camino de Santiago. Por las diferentes vías que se dirigían al extremo occidental de la Península circularon una gran cantidad de peregrinos y también de artistas para decorar los múltiples edificios que se construyeron. Éstos llevarían con ellos plantillas y modelos como apoyo gráfico a su trabajo. Aun así, hemos de señalar la inexistencia, hasta este momento, de hallazgos de libros de modelos en los territorios peninsulares. No ocurre así en otras áreas geográficas europeas, donde sí consta la existencia de varios "model books". Puede consultarse una recopilación en el estudio de R. W. SCHELLER, Exemplum: model-book drawings and the practice of artistic transmission in the Middle Ages (ca. 900 - 1470), Amsterdam, 1994. Véase también: M. FRAZER, «Byzantine art and the West», The Year 1200. A Background Survey, The Metropolitan Museum of Art, New York, 1970, pp. 185-231, especialmente p. 189; H. L. KESSLER, «Modello», Enciclopedia dell'arte medievale, Roma, 1998, vol. VIII, pp. 491-495 y D. J. A. Ross, «A late twelfth-century artist's pattern-sheet», Journal of the Warburg and Courtauld Institutes, 25, 1962, pp. 119-128.

${ }^{16}$ Sobre esta iglesia y su decoración escultórica, realizada por dos talleres distintos en las dos últimas décadas del siglo XII véase: J. M. MARTíNEZ MONTAÑÉS, «Butrera», Enciclopedia del Románico en Castilla y León. Burgos, vol. III, Aguilar de Campoo, 2002, pp. 1639-1651. el gesto pierde su contenido semántico y se convierte en un motivo decorativo ${ }^{17}$.

Otro ejemplo similar lo hallamos en un canecillo de la iglesia cántabra de San Román de Escalante. Aunque actualmente se encuentra en un estado de deterioro importante, todavía podemos ver una figura humana que se lleva ambas manos a la cabeza. Consideramos que se trata de utilización de un modelo parecido al utilizado por el escultor o taller que llevó a cabo la decoración escultórica del interior del templo. En esta iglesia se esculpió un capitel con la escena de la Matanza de los Inocentes, donde tres figuras femeninas se mesan los cabellos ${ }^{18}$. En nuestra opinión, el gesto,

${ }^{17}$ I. M. Frontón señala la relación iconográfica de la figura representada en este canecillo y la de san José, del capitel con escenas de la infancia de Cristo procedentes del claustro de Santo Domingo de Silos. Para esta autora, el artista sigue un modelo de gran pervivencia a lo largo de este período, pero que en este caso ha perdido ya su significado inicial. Sobre esto véase: I. M. FRONTÓN SIMÓN, «La representación de la Natividad en la escultura románica: un ejemplo de la irradiación silense por la periferia castellana», Actas del VIII Congreso Español de Historia del Arte (CEHA), Cáceres 1990, t. I, Mérida, 1992, pp. 55-61, especialmente p. 56.

${ }^{18}$ El gesto de mesarse los cabellos, de clara autolesión es utilizado en la plástica románica para plasmar el dolor, la impotencia y el sufrimiento ante la pérdida de un ser querido. Es utilizado, fundamentalmente, en la representación del tema de la Matanza de los Inocentes y en la plasmación de cortejos fúnebres en escenas de carácter funerario. Se trata, además, de un gesto procedente de una práctica ritual real, ya que era un comportamiento frecuente en los cortejos fúnebres en diversas culturas del mundo antiguo. Como consecuencia de ello, fue trasladado tanto al campo literario como artístico ya en época antigua y continuó siendo un motivo muy utilizado por escritores y artistas a lo largo de todo el período medieval. Sobre este gesto y su significado véase: $M$. BARASCH, Gestures of Despair..., pp. 23-24; E. GOMBRICH, «Gesto ritualizado y expresión en el arte», La imagen y el ojo. Nuevos estudios sobre la psicología de la representación pictórica, Madrid, 2000, pp. 74-75; E. PANOFSKY, Tomb Sculpture Its changing aspects from Ancient Egypt to Bernini, New York, 1992; H. PEDRINA, I gesti del dolore nella ceramica attica (VI-V secolo), Venezia, 2001 y H. A. SCHAPIRO, »The Iconography of Mourning 
con significado y significante en esta escena, fue despojado de tales para la decoración del exterior del templo, donde fue utilizado como mero elemento ornamental. El artista aisló una única figura en el canecillo, de manera que su actitud perdió todo su contenido semántico primario, adquiriendo uno nuevo al ser convertido en un motivo decorativo ${ }^{19}$.

\section{LA DESCONTEXTUALIZACIÓN CASUAL E "INTENCIONADA"}

Por último, creemos que existen también casos en los que los dos tipos de descontextualización estarían combinados. Se trata de representaciones descontextualizadas desde el punto de vista casual, ya que se encuentran fuera del ámbito original en el que fueron creadas o bien deterioradas por el paso del tiempo. Y, por otro lado, son obras en las que el papel jugado por el artista ha podido motivar, asimismo, una descontextualización "intencionada".

Como muestra citaremos dos ejemplos bien representativos: el primero de ellos se encuentra relacionado con un canecillo actualmente custodiado en una de las pandas del claustro de Santillana del Mar (Cantabria), que representa a una figura sedente que alza su brazo derecho y coloca

in Athenian Art», American Journal of Archaeology, 95.4, 1991, pp. 629-656

${ }^{19}$ Puede verse una reproducción de este canecillo en: M. A. GARCÍA GUINEA, «Escalante» Enciclopedia del Románico. Cantabria. (I) La Costa, Aguilar de Campoo, 2007, pp. 241-258, concretamente en p. 249. Este autor describe a la figura esculpida en el canecillo como "Figura humana, muy gastada, que parece cogerse la cabeza con las manos".

Algo similar a lo que ocurre en San Román de Escalante, podemos apreciarlo en otras iglesias románicas, como en varios canecillos de San Martín de Frómista y en el templo segoviano de San Miguel de Fuentidueña. Para estos dos últimos ejemplos no hemos podido encontrar la muestra plástica inserta en un contexto iconográfico mayor, que después pudo ser aislado como motivo independiente por el escultor en un canecillo. la palma de su mano ante la mejilla (Fig. 7). En primer lugar, nos encontramos ante una obra que es un caso claro de descontextualización casual, producida por el devenir del tiempo: el canecillo ha sido retirado de su ubicación original en un alero de la Colegiata, de manera que el personaje ha perdido toda posibilidad de ser identificado correctamente y con toda seguridad, tanto por su actitud como por la posible relación iconográfica con temas representados en canecillos aledaños. Sin embargo, podríamos encontrarnos, asimismo, con una descontextualización "intencionada" del gesto. En el momento en el que el canecillo fue esculpido, el artista pudo haber eliminado deliberadamente el contenido semántico del gesto que realiza el personaje y haberlo utilizado como un simple elemento decorativo en el exterior del templo.

El segundo de los ejemplos que queremos señalar, en el que podemos advertir una conjunción de descontextualización casual e "intencionada", se encuentra también en un canecillo de la portada situada en el muro sur de la iglesia Soriana de San Ginés en Reja de San Esteban (Fig. 8). Se trata de un canecillo que actualmente se encuentra muy deteriorado, aunque todavía se pueden observar a dos figuras humanas muy esquemáticas, con el cuerpo de perfil pero el rostro girado hacia el espectador. Tienden sus manos la una hacia la otra y las piernas se hallan una adelantada respecto a la otra. Se trata de una imagen que bien podríamos identificar como la representación de dos personajes abrazados $\mathrm{o}$, por el contrario, como dos contrincantes en una enfrentamiento cuerpo a cuerpo. Ello podría deberse a la poca pericia del artista que esculpió el tema iconográfico. Sin embargo, en esta imagen soriana, la dificultad de interpretación se acentúa aún más al encontrarnos ante una imagen tan deteriorada por las inclemencias metereológicas que el paso del tiempo impone a toda obra artística, de manera que podemos calificar 
al canecillo soriano como una obra también descontextualizada respecto a su aspecto original. A ello debemos añadir el tipo de soporte en el que se encuentra. Por todo ello, actualmente nos resulta difícil discernir si nos encontramos ante una escena de abrazo o de combate cuerpo a cuerpo.

\section{CONCLUSIONES}

En el campo de la semiótica suele señalarse que un acto de comunicación verbal ha fallado cuando el receptor no logra captar toda la información, el sentido completo, que el emisor pretende transmitirle ${ }^{20}$. Si aplicamos esta concepción a nuestro ámbito de estudio, el de la comunicación visualgestual, podríamos señalar que el receptor, es decir, el espectador de la obra, no es capaz de comprender el mensaje enviado por el emisor, es decir, el artista.

Como hemos ido señalando a lo largo del trabajo, ese fallo en la comunicación gestual puede ser el resultado de diversos factores. Por un lado puede deberse a la evolución histórica de las obras de arte, que llegan a nuestros días tras haber sufrido cambios importantes respecto a su concepción original. Así, el traslado de una pieza a un museo, su recolocación en el espacio para el que fue creada o su propio deterioro físico nos lleva, en muchos casos, a tener dificultades para interpretar correctamente el significado de un gesto.

Pero, por otro lado, nos encontramos ante la problemática que plantea el papel jugado por el artista que plasma gráficamente los temas y motivos iconográficos que le han sido encargados. En muchos casos, la ambigüedad interpretativa ante la que nos podemos encontrar podría estar en función de la capacidad técnica del pintor,

\footnotetext{
${ }^{20}$ Sobre estos aspectos véase: S. GUTIERREZ ORDOÑEZ, Introducción a la Semántica Funcional, Madrid, 1989, pp. $20-21$.
}

escultor o miniaturista de llevar al campo artístico un modelo o motivo, así como su conocimiento o desconocimiento del tema o escena que está creando, en función de lo cual podríamos encontrarnos ante una posible malinterpretación en la copia de gestos, maneras, posturas y actitudes. Además, hemos de tener en cuenta también su propia intencionalidad, así como los modelos y fórmulas iconográficas de los que disponía pueden conllevar, asimismo, una descontextualización de los gestos el arte románico.

Para finalizar, hemos de señalar que el fenómeno de la descontextualización del gesto que hemos analizado en este trabajo no es propio únicamente del arte románico. La malinterpretación de gestos y atributos a causa de diversos factores la encontramos ya en las manifestaciones artísticas de otros períodos y culturas. Así por ejemplo, en época romana, muchas de las esculturas griegas trasladadas a Roma fueron reinterpretadas, creándose toda una tradición oral que describía e inventaba leyendas en función de las nuevas interpretaciones e identificaciones de las figuras, fenómeno que los antropólogos han denominado iconatropía $^{21}$.

\footnotetext{
${ }^{21}$ Sobre este fenómeno en el mundo romano, así como su traslado a época actual véase: C. M. KEESLING, «Misunderstood gestures: Iconatrophy and the Reception of Greek Sculpture in the Roman Imperial Period», Classical Antiquity, 24.1, 2005, pp. 41-79.

Otro ejemplo significativo de iconatropía, a caballo entre el arte antiguo y medieval, lo hallamos en la evolución sufrida por el mito de Perseo y la Gorgona, que tuvo una continuidad iconográfica a lo largo de la Edad Media, sobre todo en el campo de la miniatura, en manuscritos de astronomía donde se representó gráficamente la constelación de Perseo. En un principio, esta constelación estaba representada por la figura mitológica del guerrero que portaba en su mano la cabeza de la Medusa. Así ocurre en un manuscrito carolingio del siglo IX conservado en Leyden, Bibliothèque Universitaire, Ms. Voss. lat. Q. 79. Sin embargo, poco a poco se produjo una evolución de la iconografía, sobre todo en los manuscritos árabes. Los miniatu-
} 


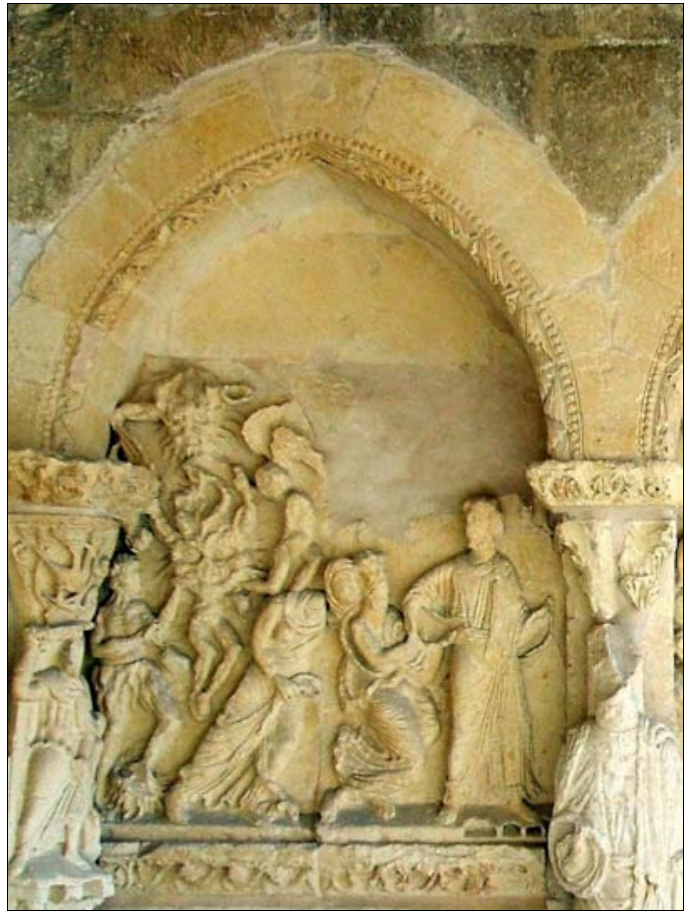

- Fig. 1. Asir la mano. Descenso al Limbo. Relieves del pórtico. Armentia (Álava), Basílica de San Prudencio. Siglo XII

ristas musulmanes, que seguramente ignoraban el mito antiguo, interpretaron la cabeza de la medusa como un ser demoníaco. Así lo demuestran dos manuscrito hoy conservado en Paris, Bibliothèque de l'Arsenal, Ms. 1016 y en Paris, Bibliothèque nationale de France, Cod. Arabe 5036, fol. 68. Nos encontraríamos ante un caso claro de iconatropía, es decir, de malinterpretación de la identidad de un mito y su iconografía. Sobre este caso véase: E. PANOFSKY - F. SAXL, La mythologie classique dans l'art medieval, SaintPierre de Salerne, 1990, pp. 39-46.

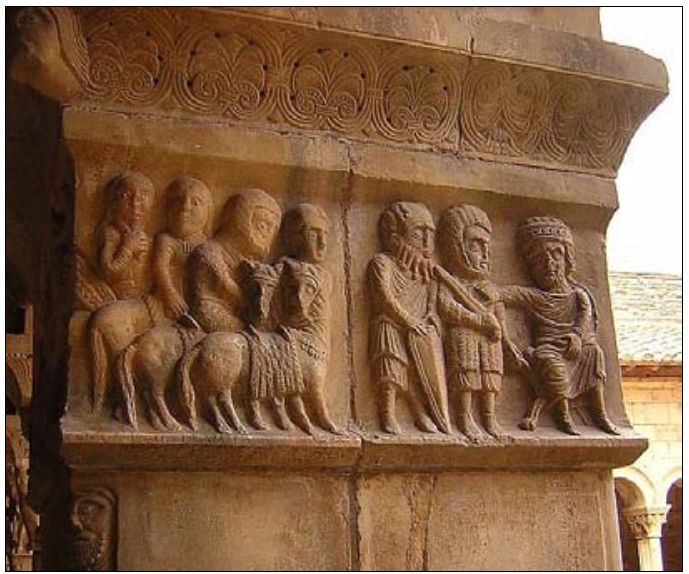

- Fig. 2. Matanza de los inocentes. Capitel de pilastra. Panda sur del claustro. Elna (Rosellón), catedral de Santa Eulalia. Siglo XII

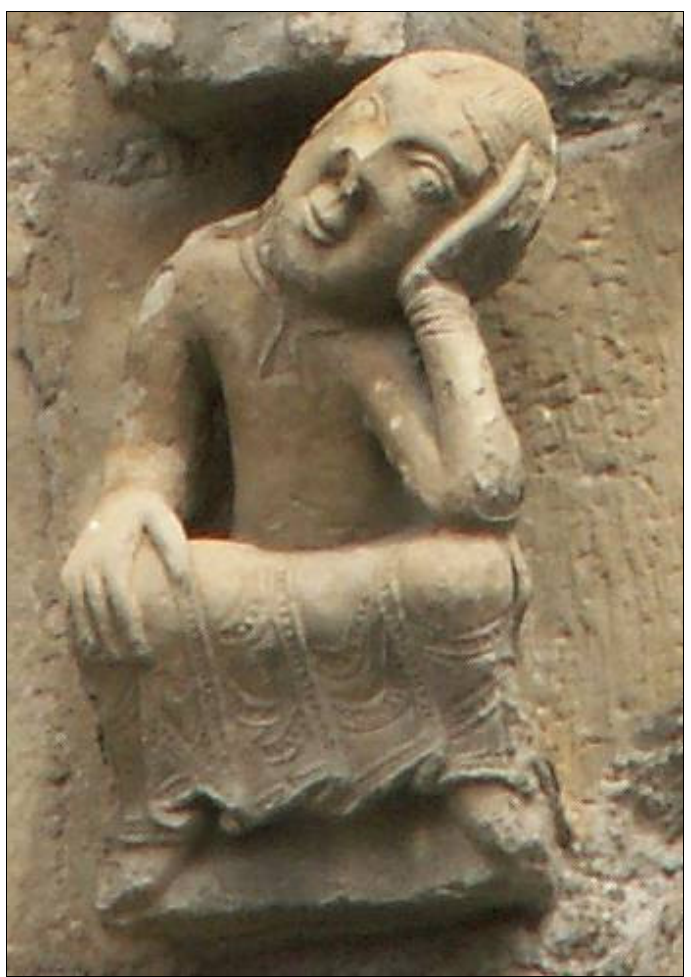

- Fig. 3. Figura descontextualizada. Lado izquierdo de la portada. Sangüesa, iglesia de Santa María. Siglo XII 


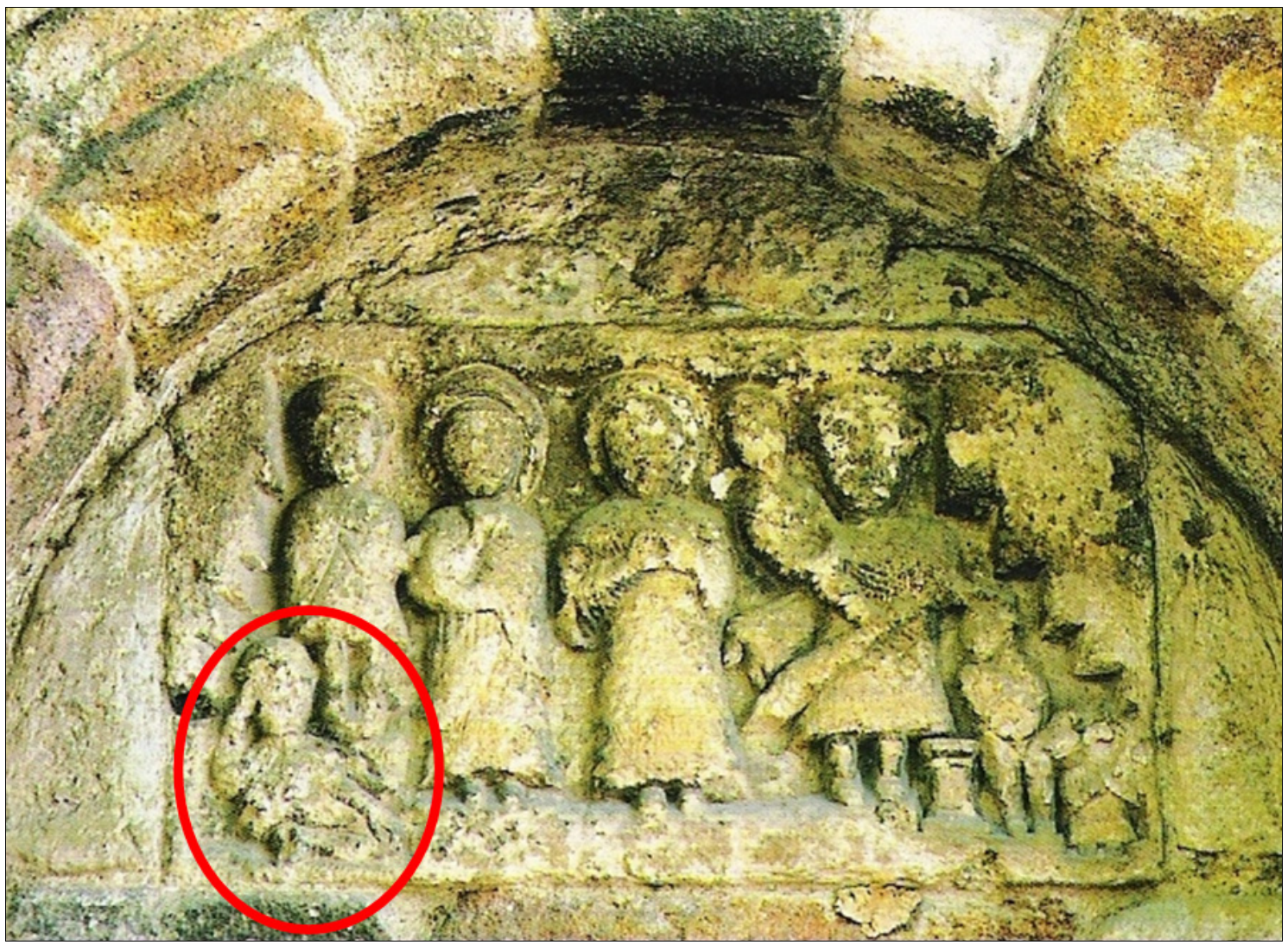

- Fig. 4. Figura deteriorada por el paso del tiempo. Relieve empotrado en el exterior del templo. Ábside del evangelio. Zamora, iglesia de San Cipriano. Finales siglo XI.

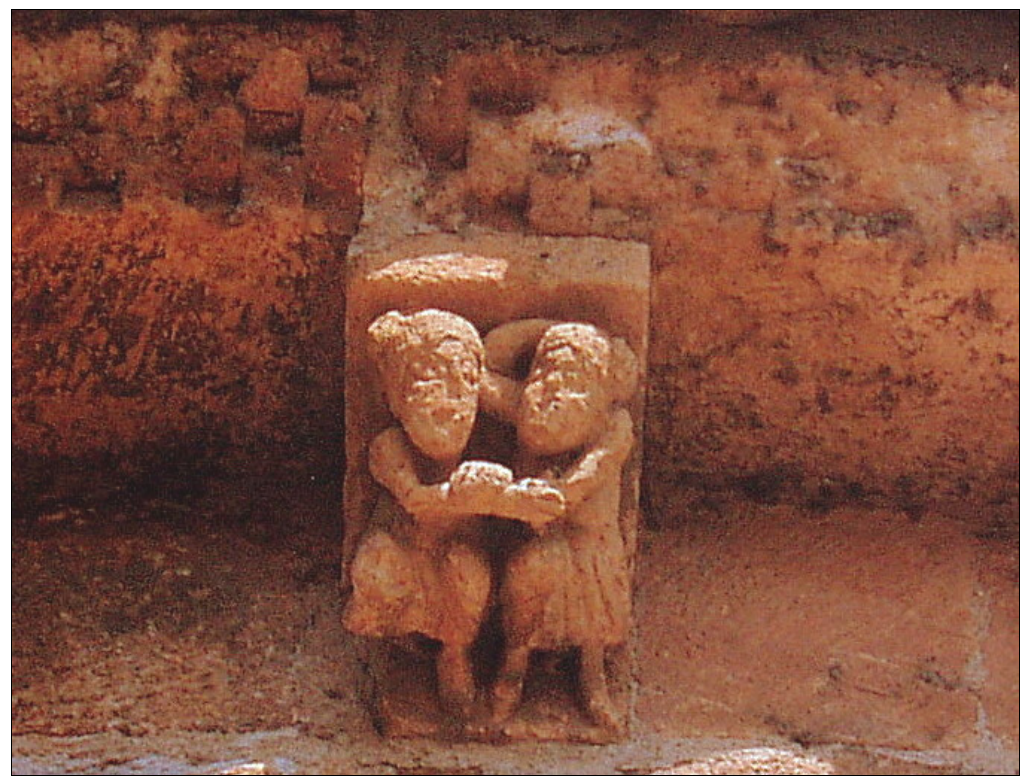

- Fig. 5. ¿Escena de lucha?. Canecillo de la cabecera. Zamora, Iglesia de San Claudio de Olivares. Siglo XII 


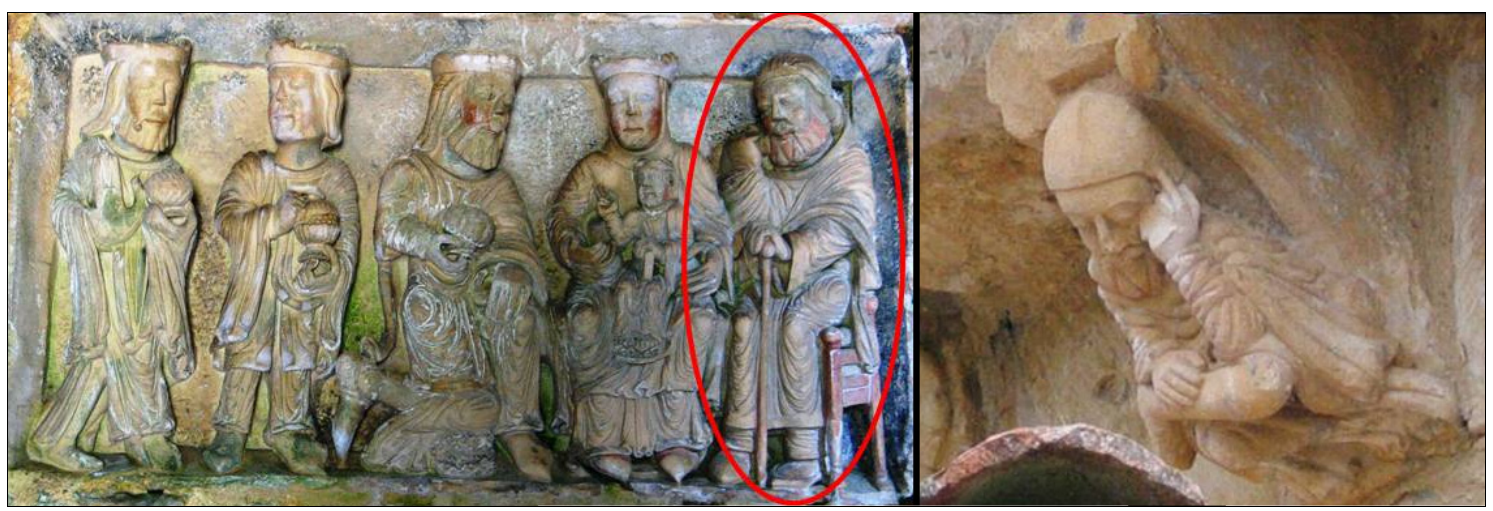

- Fig. 6. Comparativa entre la escena de la Epifanía y un personaje no identificado. Relieve empotrado en el interior del templo y canecillo del exterior. Butrera (Burgos), iglesia de Nuestra Señora de la Asunción. Siglo XII-XIII

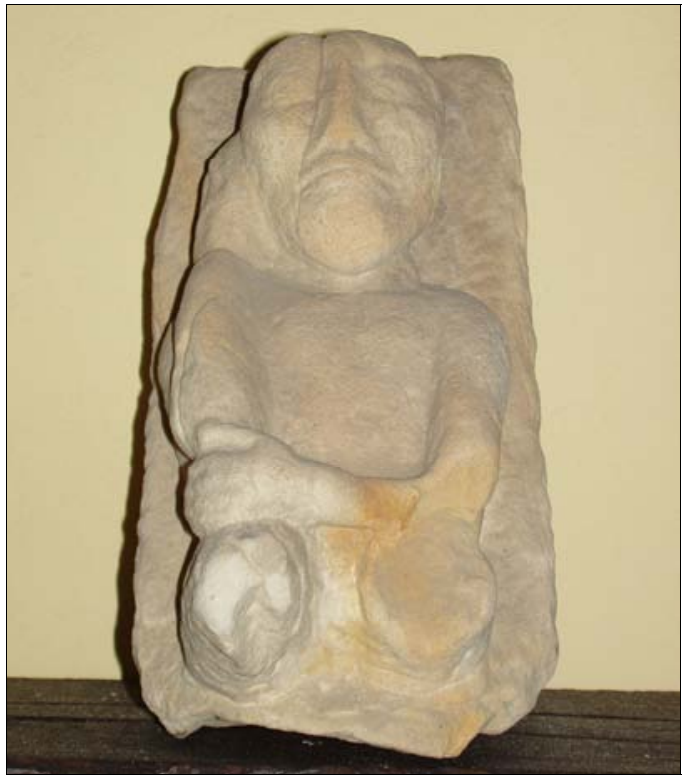

- Fig. 7. Canecillo descontextualizado. Hoy custodiado en una de las pandas del claustro. Santillana del Mar (Cantabria), Colegiata de Santa Juliana. Siglo XII

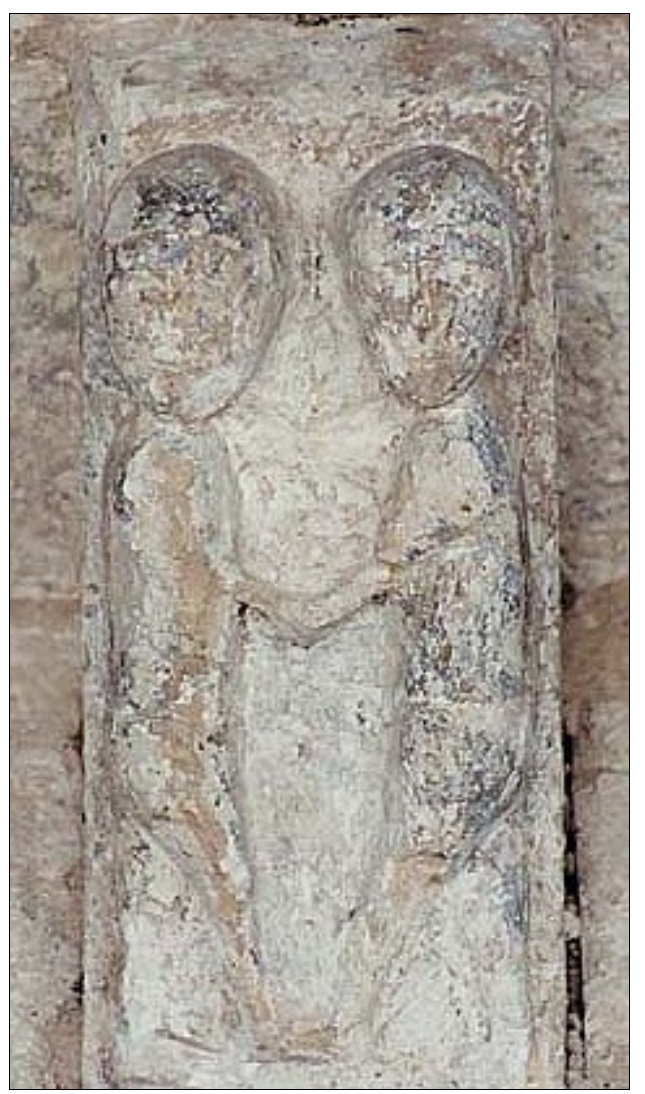

- Fig. 8. Escena ambivalente. Canecillo exterior. Reja de San Esteban (Soria), iglesia de San Ginés. Siglo XII 